\title{
Low Grade Neuroendocrine Lesion
}

National Cancer Institute

\section{Source}

National Cancer Institute. Low Grade Neuroendocrine Lesion. NCI Thesaurus. Code C155864.

A neoplastic lesion with neuroendocrine differentiation and histological features of low grade. 